\title{
ЭССЕНЦИАЛЬНАЯ ГИПОТОНИЯ У СТУДЕНТОВ ОБУЧАЮЩИХСЯ В ВУЗЕ
}

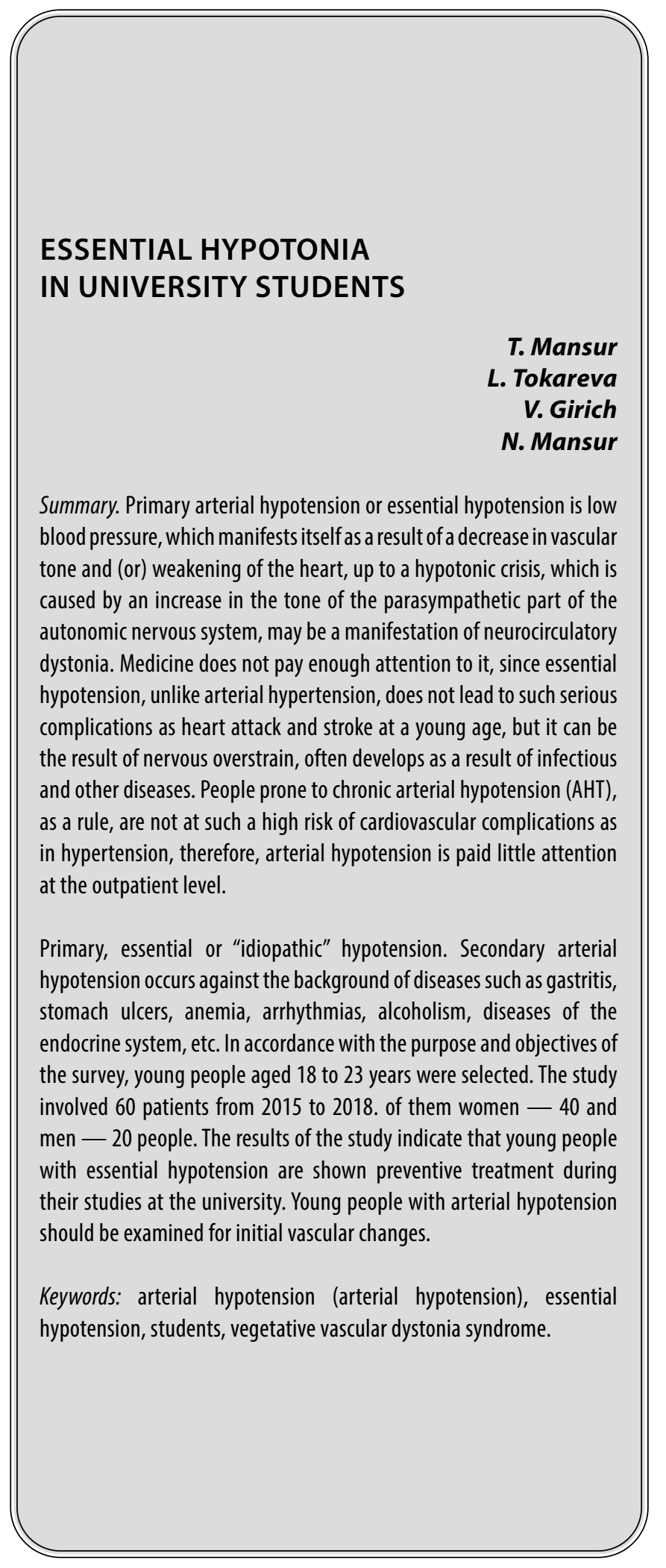

\author{
Мансур Татьяна Ивановна \\ К.м.н., дочент, РУДН \\ m-dasha07@mail.ru \\ токарева Людмила Георгиевна \\ Ассистент, РУДН \\ lyuda.tokareva.79@mail.ru \\ Гирич Валентина Стефановна \\ К.б.н., старший преподаватель, РУДН \\ girich.valentinas@gmail.com \\ Мансур Нумман \\ К.м.н., врач невролог, ГКБ 64, г. Москва \\ d-64-158@mail.ru
}

Аннотация. Первичная артериальная гипотензия или эссенциальная гипотония - низкое кровяное давление, которое проявляется в результате снижения сосудистого тонуса и (или) ослабления работы сердца, вплоть до гипотонического криза, которая обусловлена повышением тонуса парасимпатического отдела вегетативной нервной системы, может быть проявлением нейроциркуляторной дистонии. Медицина не уделяет ей должного внимания, так как эссенциальная гипотония в отличии от артериальной гипертензии не приводит к таким серьезным осложнениям, как инфаркт и инсульт в молодом возрасте, но она может быть результатом нервного перенапряжения, часто развивается как следствие инфекционных и других заболеваний. Люди, склонные к хронической артериальной гипотензии (АГт), как правило, не подвержены такому высокому риску сердечно-сосудистых осложнений, как при гипертонии, поэтому артериальной гипотонии уделяется мало внимания на амбулаторном уровне.

Первичная, эссенциальная или «идиопатическая» гипотония. Вторичная артериальная гипотония возникает на фоне заболеваний, таких как гастрит, язва желудка, анемия, аритмии, алкоголизм, заболевания эндокринной системы и др. В соответствии с целью и задачами обследования отобраны молодые люди в возрасте от 18 до 23 лет. В исследовании участвовали 60 пациентов в период с 2015 по 2018 годы. из них женщин - 40 и мужчин - 20 человек. Полученные результаты исследования свидетельствуют о том, что лицам молодого возраста, с эссенциальной гипотонией показано профилактическое лечение в период обучения в вузе. Молодые лица с артериальной гипотонией должны быть обследованы на предмет наличия у них начальных сосудистых изменений.

Ключевые слова: артериальная гипотония (артериальная гипотензия), эссенциальная гипотония, студенты, синдром вегетативно сосудистой дистонии. 
$\boldsymbol{9}$ ссенциальная гипотония (артериальная гипотензия) встречается по данным литературы приблизительно у $15 \%$ больных терапевтических отделений. Обнаружив артериальную гипотонию у пациента, врач должен первоначально решить, является ли это вариантом нормы (физиологическая гипотония) или симптомом болезни и какой именно болезни (патологическая гипотония). Медицина на амбулаторном уровне не уделяет ей должного внимания, так как эссенциальная гипотония в отличии от артериальной гипертензии не приводит к таким серьезным осложнениям, как инфаркт и инсульт в молодом возрасте, но она может быть результатом нервного перенапряжения, часто развивается как следствие инфекционных и других заболеваний. Люди, склонные к артериальной гипотензии (АГт), как правило, не подвержены высокому риску сердечно-сосудистых осложнений, поэтому данной патологии уделяется мало внимания в амбулаторном звене.

Артериальная гипотония сопровождается низкими цифрами артериального давления (снижение артериального давления -90 мм рт. ст. и ниже систолического давления или 60 мм рт.ст. среднего диастолического артериального давления), может беспокоить головокружение, зрительные нарушения (скотомы), головные боли и общее состояние усталости и слабости. У молодых лиц оно может быть следствием нервного перенапряжения, развивается как последствие инфекционных и других заболеваний, а также при недостаточном или беспорядочном питании, в дисбалансе часов отдыха и труда $[2,4]$.

В авторитетных справочниках есть исключительно так называемый синдром вегетативной сосудистой дистонии (СВСД), а человек с СВСД по гипотоническому типу считается здоровым. Российский ученый невролог Е.В. Шмидт (1983) считал термин вегетативная сосудистая дистония (ВСД) предпочтительным в тех случаях, когда вегетативная дисфункция выходит за рамки сердечно-сосудистых расстройств, а нейроциркуляторная дистония (НЦД) укладывается в эти рамки. Существуют несколько теорий возникновения АГт: эндокринная, вегетативная, нейрогенная, гуморальная и метаболическая $[1,2]$.

Лица, склонные к артериальной гипотензии (АГт), как правило, не подвержены столь высокому риску сердечно-сосудистых осложнений, как лица с артериальной гипертонией, поэтому ей уделяется значительно меньше внимания. Не разработаны достаточно четко основные диагностические и профилактические стандарты, и лечебные стандарты. АГт иногда сочетается с другими признаками вегетативной дисфункции, с признаками ваготонии $[5,7,8,12,13]$. К вариантам физиологической артериальной гипотонии относят артериальную гипо- тензию как индивидуальную норму (имеющую наследственный конституциональный характер), адаптивную компенсаторную гипотензию (у жителей высокогорья, тропиков и субтропиков) и гипотензию повышенной тренированности (встречается среди спортсменов).

Первичная артериальная гипотония, как самостоятельное заболевание, включает в себя случаи идиопатической ортостатической гипотензии и нейроциркуляторной гипотензии с нестойким обратимым течением или стойкими проявлениями (гипотоническая болезнь). По международной классификации МКБ -10 первичная «идиопатическая» или эссенциальная гипотония - это самостоятельное заболевание. В качестве гипотетической причины первичной гипотензии указывается наследственная особенность стенок сосудов - снижение эластичности (дряблость) артерий. Это способствует снижению их напряжения и уменьшению периферического сопротивления для циркулирующей крови. Снижение атмосферного давления и жара способствуют нарастанию симптомов низкого давления. По одной из теорий, первичная гипотония является особой формой неврозоподобного заболевания сосудодвигательных центров головного мозга, так как в её развитии очень большая роль может принадлежать длительному психоэмоциональному перенапряжению и стрессу $[3,5,6]$.

В ряду симптоматической (вторичной) артериальной гипотонии в литературе рассматриваются острые (коллапс, шок) и хронические формы, обусловленные органической патологией сердечной, нервной, эндокринной системы, гематологическими заболеваниями, интоксикациями. АГт возникает на фоне таких заболеваний, как остеохондроз шейного отдела позвоночника, язва желудка, анемия, аритмии, заболевания сердца, алкоголизм, заболевания эндокринной системы или органов дыхания, сердечной недостаточности, интоксикации, как побочное действие некоторых лекарственных препаратов (например, их передозировка при лечении гипертензии) $[1,2,7,9]$. После обильного приёма пищи у здоровых людей систолическое АД в послеобеденный период обычно снижается не более чем на 5 мм рт. ст. Механизм в постпрандиальной гипотонии (ППГ) - это результат депонирования крови в органах желудочно-кишечного тракта (ЖКТ) после и во время приема пищи [7]. У спортсменов при постоянной физической нагрузке появляется так называемая «гипотония тренированности» $[1,2,3,6]$.

В настоящее время установлено, что риск развития сердечно - сосудистых осложнений значителен как при чрезмерно высоких, так и при низких значениях АД. По данным исследования Ohasama Stady (2000) уровни среднесуточного САД >134 и <119 мм рт. ст, 


\section{Эссенциальная гипотония}

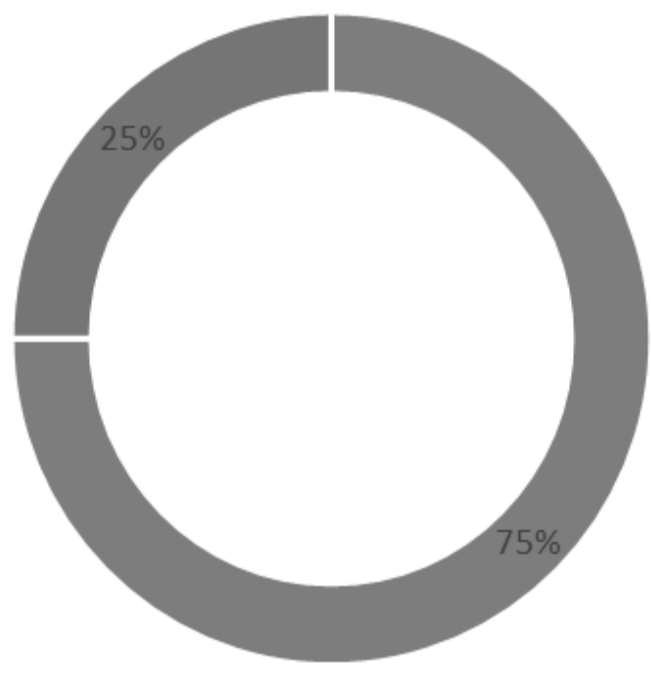

- 1 группа - 2 группа

Рис. 1. Процентное распределение молодых лиц с эссенциальной гипотонией в возрасте 18-23 лет по группам $(\mathrm{n}=40)$

\section{Артериальное давление}

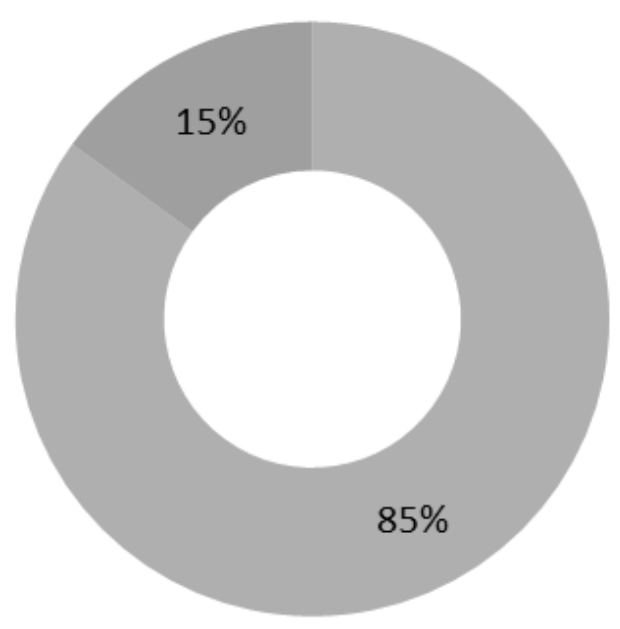

110-100/70-65мм рт ст 95-90/60-55 мм рт ст

Рис. 2. Процентное распределение значений АД у студентов не зависимо от группы 


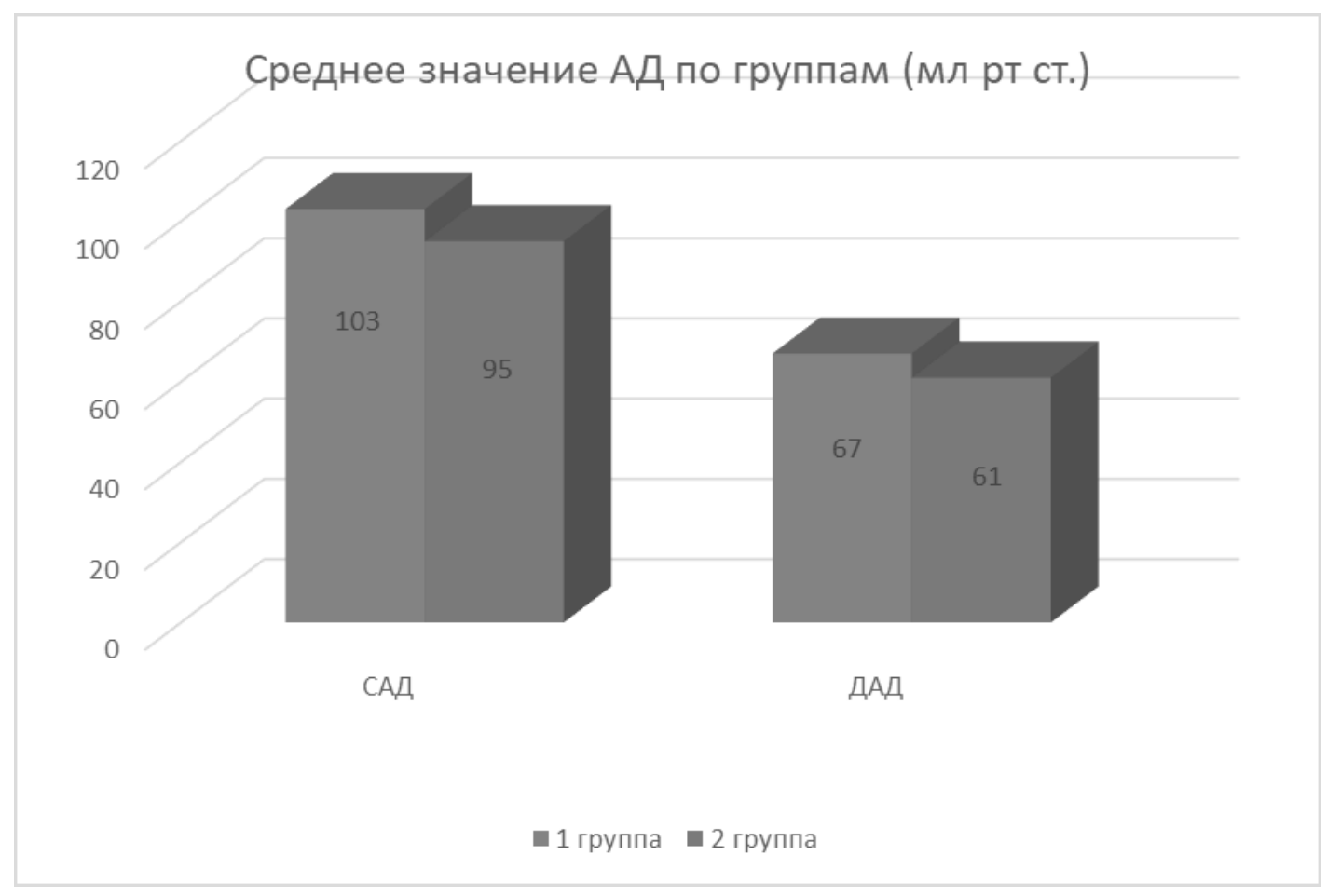

Рис. 3. Средние значения систолического артериального давления (САД) и диастолическое давление (ДАД) у студентов 1 и 2 групп

среднесуточного ДАД > 79 и <64 мм рт. ст. связаны с увеличением риска внезапной смерти $[9,10,11]$. Поэтому в настоящее время проблема артериальной гипотонии заслуживает внимания.

\section{Цель и залачи исслеАОвания}

Выявить и проследить в условиях амбулаторно-поликлинической практики артериальную гипотонию у лиц молодого возраста, в частности, студентов обучающихся в ВУЗе.

\section{Материалы и метолы}

В соответствии с поставленной целью и задачами исследования были отобраны молодые люди в возрасте от 18 до 23 лет обращавшихся в КДЦ РУДН г. Москвы при прохождении профилактического осмотра или по обращаемости, и на кафедре общей врачебной практики (ОВП) РУДН за период с 2015 по 2018 гг. С подтвержденным диагнозом артериальная гипотензия после обследования оказалось 60 пациентов из них женщин - 40, мужчин - 20. Всем пациентам были проведены следующие исследования: электрокардиография (ЭКГ), ультразвуковая допплерография (УЗДГ) магистральных артерий головы и шеи (МАГ), реоэнцефалография (РЭГ)-проводилась на базе кафедры ОВП РУДН.

\section{Результаты исслеАования и их обсужАение}

Проводя обследования молодых лиц $(\mathrm{n}=60)$ с эссенциальной гипотонией все обследуемые, разделились на две группы. Первую группу составили студенты, не предъявляющие жалоб, а во вторую группу вошли студенты с клиническими симптомами, которые проявлялись такими жалобами, как головная боль, утомляемость, рассеянность внимания, сонливость, эмоциональная лабильность. Жалобы беспокоили особенно при утомлении физическом или эмоциональном, а также при изменении атмосферного давления и при магнитных бурях. Студенты распределились следующим образом: 1 группа - составила 75\%; 2 группа - составил 25\%; (см. рис. 1).

Лицам с АГ ежедневно измерялось артериальное давление в течение месяца. В результате выявились следующие показатели артериального давления у пациентов: АД= от 95/60 мм рт ст.-до 90/55 мм рт ст.у $15 \%$ обследуемых; артериальное давление колебалось в пределах нижней границы нормы от 110/70 мм рт ст и до 100/65 мм рт ст - у 85\% обследуемых, (см. рис. 2).

По группам выявились следующие показатели артериального давления у студентов: в первой груп- 


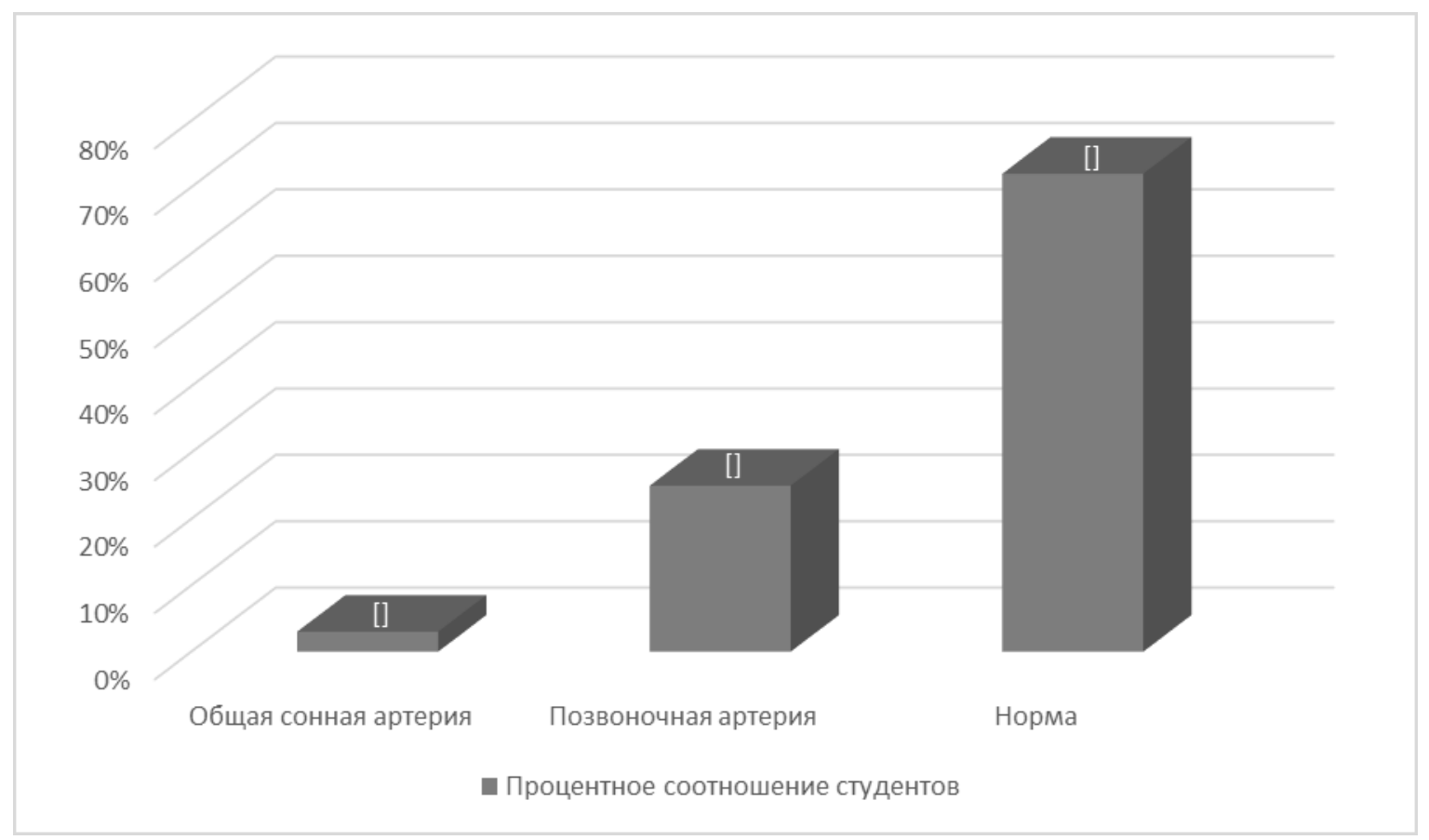

Рис. 4. Соотношение изменений ССК в бассейнах ОСА и ПА у студентов

пе АД колебалось в пределах от110/70 мм рт ст.-до 95/60 мм рт ст.—у всех обследуемых и составило средний показатель САД 103 мм рт ст. и ДАД 67 мм рт ст.; во второй группе артериальное давление колебалось от 100/65 мм рт ст до 90/55 мм рт ст. у обследуемых, что составило среднее значение САД 95 мм рт ст. и ДАД 61 мм рт ст. Проанализировав цифры артериального давления у студентов по группам, получили средние значения АД систолического и диастолического давления. На рисунке № 3 представлены средние значения АД (САД и ДАД) в 2-х обследуемых группах.

В результате были получены данные, свидетельствующие о том, что у обследуемых во второй группе (n=15ст.) отмечались более пониженные цифры артериального давления, по сравнению с первой группой $(\mathrm{n}=45 \mathrm{ct}$.), хотя у некоторых они и укладывались в нижнюю границу возрастной нормы. У всех обследуемых во 2 группе отмечались жалобы и некоторые вегетативные проявления, например влажноватые и холодные стопы ног и ладони рук, иногда беспокоила утомляемость и низкая работоспособность, временами отмечалось нарушение сна, раздражительность или сонливость, головная боль, трудность сосредоточиться.

Всем обследуемым в 2-х группах проводилась ультразвуковая допплерография магистральных артерий головы и шеи. Пациентам измерялись скоростные показатели кровотока по общим сонным артериям (OCA) и позвоночным артериям (ПА). Были выявлены незначительные изменения, такие как снижение систолической скорости кровотока (ССК) по магистральным артериям головы (МАГ) по сравнению с нормой, однако все они были гемодинамически не значимые, а некоторые укладывались в нижнюю границу нормы. По позвоночным артериям (ПА) снижение ССК выявилось в 25\% случаев, по общим сонным артериям (ОСА) в 3\% случаев, в двух бассейнах одновременно выявилось снижение у $1 \%$ лиц и в норме ССК отмечалось у $72 \%$ обследуемых лиц. Во всех 2 группах обследуемых студентов были выявлены изменения скоростных показателей кровотока по магистральным артериям головы, в частности снижение ССК по ПА, в бассейне ОСА изменения выражались в гемодинамически незначимом снижении систолической скорости кровотока, в пределах нижней возрастной границы нормы.

Всем обследуемым студентам из 2-х групп проводился неинвазивный метод исследования реоэнцефалография (РЭГ) церебральных сосудов. Пациентам определялся тонус сосудов. По данным РЭГ отмечались следующие изменения:

1. неустойчивость сосудистого тонуса, превалирует гипотонус со сниженным пульсовым наполнением - дистонический тип выявлен у 70\% обследуемых;

2. измененный сосудистый тонус, эластичность сосудистой стенки изменена с затруднением кровообращения в бассейнах ПА - церебральная 
ангиодистония по гипотоническому типу выявлялась у $3 \%$ студентов из двух групп;

3. тонус сосудов в пределах возрастной нормы выявлен у $27 \%$ из двух групп.

Данные обследования ЭКГ у студентов двух групп соответствовали возрастной норме.

После проведенного обследования были даны рекомендации пациентам по лечению с учетом жалоб и данных изменений по дополнительным методам обследования. В первой группе рекомендовали назначать витамины группы B, E, C, кофеин содержащие препараты, лечебную физкультуру, массаж воротниковой зоны, водные процедуры (контрастный и циркулярный души), направленные на повышение сосудистого тонуса. Во второй группе рекомендовали дополнительно назначать все препараты ноотропной группы: ноотропил (пирацетам по 200 мг или 400 мг, прием 2 раза в день, курсовое лечение 2-4 недели), церебролизин (по 1,0 мл - 5,0 мл в/м, к/д, на курс № 10, для повышения эффективности лечения проводились повторные курсы). Растительные адаптогены: настойка китайского лимонника (прием по 15 капель 1-2 раза в день, через 3-4 часа после приема пищи или перед едой за полчаса, его разводят водой, принимают на протяжении 3-4 недель.), экстракт элеутерококка (прием по 20-25 капель или 1 чайная ложка, растворить в 50 мл воды, пить 2 раза в день.), препараты, улучшающие микроциркуляцию: никошпан 2т в день, на курс лечения14 дней), мексидол по 125-250 мг, по 1 таб. 3 раза/сут; длительность лечения от 3 до 6 недель. Проводимое лечение было эффективным и у всех студентов отмечалось улучшение общего самочувствия, прошли головные боли, проходили или уменьшались вегетативные проявления, повышалась работоспособность и улучшалась память.

\section{Зак^ючение и обсужление полученных результатов}

Проведенные исследования показали, что студенты страдающие эссенциальной гипотонией уже имеют начальные сосудистые изменения, что подтверждается такими методами обследования, как РЭГ и УзДГ МАГ и соответственно отношение к лицам, страдающим артериальной гипотонией, должно быть таким же, как к лицам страдающим артериальной гипертензией (АГ), бронхиальной астмой, гастритом и другими заболеваниями, то есть рассматривать первичную артериальную гипотензию как болезнь (патологию) с соответствующим нозологическим понятием. Пациентам с эссенциальной гипотонией рекомендуется: постоянный контроль уровня АД, профилактическое лечение в санаториях профилакториях, регулярное наблюдение у врача общей практики, в амбулаторных условиях проводить дообследование: мониторинг артериального давления в течение четырех недель; РЭГ и УзДГ сосудов головы и шеи. Молодые лица с эссенциальной гипотонией должны быть обследованы на предмет наличия у них начальных сосудистых изменений.

Врач общей практики должен начинать первичную профилактику студентам с АГт при наличии жалоб. Целесообразно назначение базисной терапии: ноотропные препараты (ноотропил, пирацетам), растительные адаптогены (настойка китайского лимонника, женьшеня, экстракт элеутерококка). а также показано при низких цифрах артериального давления сопровождающееся жалобами назначение препаратов кофеинового ряда, эрготамин, кофетамин. Показаны назначения немедикаментозных методов лечения: массаж воротниковой зоны, водные процедуры, направленные на повышение сосудистого тонуса (контрастный душ, циркулярный душ и др.).

\section{ЛИТЕРАТУРА}

1. А.И. Абдрахманова, Н.А. Цибулькин. Артериальная гипотензия в клинической практике/Вестник Современной Клинической Медицины.-2013 г.Том 6 приложение 1.- С. 20-24

2. Барсуков А.В., Васильева И.А. Клинические и патофизиологические аспекты постпрандиальной гипотензии//Клиническая патофизиология 2004 г. № 2. - C. 70-74.

3. Б.В. Дривотинов., Е.Н. Апанель., А.С. Мастыкин Гипотонический криз: болезнь или следствие нейропсихосоматических особенностей человека? // Медицинский журнал.—-2007 г.-№ 1.-С. 109-113

4. К.М. Дзилихова, М.Г. Дзгоева, З.Д. Калоева, С.К. Каряева, О.А. Кагирова, А.А. Церекова Состояние регионального пульсового кровенаполнения у детей и подростков с первичной артериальной гипотензией. // Журнал Педиатрия 2015 г.Том 91 № 2C.38-41

5. Мансур Т.И., Нумман М., Русанова Е.И., Алексеев Г.И. Артериальная гипотензия у лиц молодого возраста. // Технологии живых систем. 2013 г. Т. 10. № 5. С. 055-058.

6. Михайлов А.А. Хроническая артериальная гипотензия: возможности медикаментозной коррекции. — РМЖ.2004 г. -№ 7.— C. $468-470$.

7. Тюрина Т.В. Постпрандиальная гипотензия // Врач. — 2002. -№ 12.-С. 24-26.

8. Хирманов, В.Н. Профиль артериального давления у пациентов с артериальной гипер- и гипотензией и влияние на него физиологических нагрузок /В.Н. Хирманов, Т.В. Тюрина //Кардиология.-2002.-Т.42, N7.-С.44-46. 
9. Шабалин А.В., Гуляева, Е.Н., Торочкина, Е.Е. и др. Диагностическая значимость циркадной вариабельности артериального давления и ритма сердца в оценке клинико-функционального статуса больных с артериальной гипертензией. // Кардиология.-2005.-Т.45.-N8.-C. 45-46.

10. Интернет-журнал по функциональной диагностике. Лунина М.Д., Утехина Г.А., Шамова Н.И. Диагностика артериальной гипотензии, 2012, № 8, гоУ ДПО СПб МАПО.

11. Швец, Д.А. Системный анализ гемодинамических и антропометрических параметров у больных при первичной артериальной гипотензии / Д.А. Швец, А.В. Познякова, В.И. Вишневский [и др.] // Человек и его здоровье. — 2005 г. — № 4. - С.73-79.

12. А.В. Барсуков, А.М. Каримова, Ю.Ш. Халимов, Д.В. Глуховской Проблема артериальной гипотензии у пациентов молодого возраста в клинической практике // Вестник Российской Военно-медицинской Академии 3 (55) - 2016. С. $30-35$

13. И.Н. Исаева, Д.И. Маракушин Особенности адаптационных реакций сердечно-сосудистой системы у лиц молодого возраста с артериальной гипотензией // Научные Ведомости. Серия Медицина. Фармация. 2016 г. № 5 (226). Выпуск 33. С. 31-38

( Мансур Татьяна Ивановна ( m-dasha07@mail.ru ), Токарева Людмила Георгиевна ( lyuda.tokareva.79@mail.ru ),

гирич Валентина Стефановна ( girich.valentinas@gmail.com ), Мансур Нумман ( d-64-158@mail.ru).

Журнал «Современная наука: актуальные проблемы теории и практики»

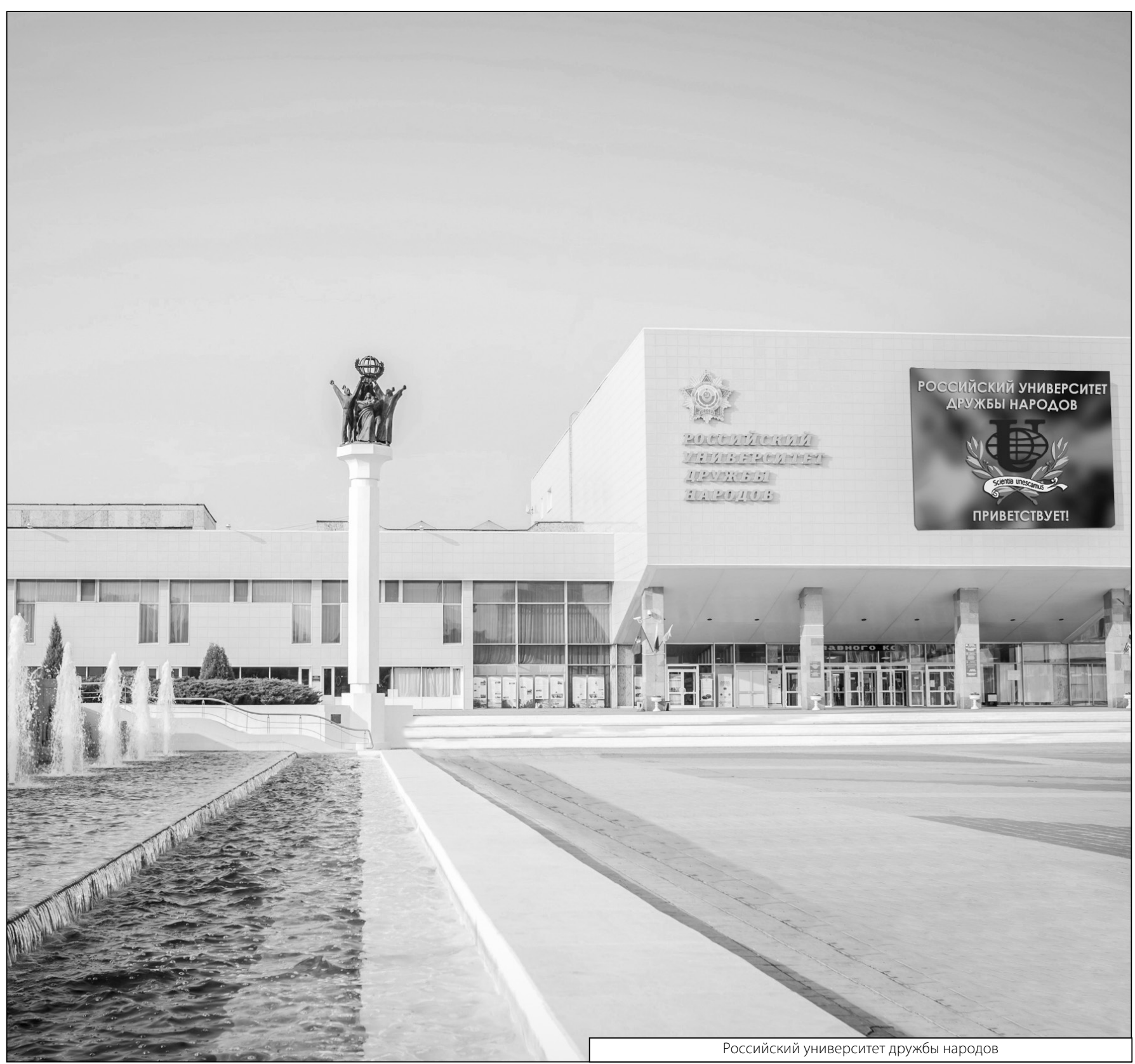

